\title{
DOCUMENTATION OF THE LOGICAL IMPUTATION \\ USING THE PANEL STRUCTURE OF \\ THE 2003-2008 GERMAN SAVE SURVEY
}

\author{
Michael Ziegelmeyer
}

173-2009

๑ mea-Mannheim Research Institute for the Economics of Aging

L13, 17_D-68131 Mannheim_Phone +49 621 181-2773/1862_Fax +49 621 181-1863_www.mea.uni-mannheim.de 


\title{
Documentation of the logical imputation using the panel structure of the 2003-2008 German SAVE Survey ${ }^{1}$
}

\author{
Michael Ziegelmeyer ${ }^{\dagger}$
}

February 2009

\begin{abstract}
This paper documents the implementation of a logical imputation based on the panel structure of the 2003 to 2008 waves of the German SAVE dataset. A new release of the waves 2003-2008 will be available from June 2009. The concept and the principles of the underlying logical panel imputation are described. Furthermore, the method applied to logically impute each variable is briefly commented. The logical panel imputation of the SAVE dataset reduces decisively the number of missing values for some variables. In some cases more than $50 \%$ of all missing values can be replaced by proper values.
\end{abstract}

Key words: Item-nonresponse, imputation, panel data, SAVE

JEL classification: C81

\footnotetext{
${ }^{1}$ The author would like to thank Michela Coppola for very helpful support.

${ }^{\dagger}$ Mannheim Research Institute for the Economics of Aging (MEA); University of Mannheim; L13,17; 68131 Mannheim; Germany; Email: Ziegelmeyer@mea.uni-mannheim.de
} 


\section{INTRODUCTION}

The problem of item-nonresponse is widespread in micro datasets. Households or individuals, who are not able or willing to respond to questions, leave the resulting dataset similar to a "rag rug”. Researchers who want to analyse such datasets have therefore to deal with serious difficulties. Mainly two problems arise: First, if multivariate procedures are used to analyze certain effects, all the variables of each unit (household or individual) must be complete. If there is one missing value in a variable, the variable has to be dropped or the sample size has to be reduced by all units containing missing values. This observed-case analysis can lead to a serious reduction of the sample size and the connected loss of efficiency. Additionally, the sample size varies with the question investigated, since different variables are needed for the analysis. Second, the missing value of a variable might not be random and related to certain characteristics or the environment of the respondent, so that estimations based on only observed cases might lead to biased results.

There are different methods to deal with item-nonresponse. Rässler and Riphahn (2006) outline four approaches (complete case analysis, weighting, imputation, model-based procedures) and discuss their strengths and weaknesses. The authors conclude "that $a$ multiple imputation procedure seems to be the best alternative at hand to account for missingness and to exploit all available information (Rässler and Riphahn 2006, p. 229).” This procedure was chosen for the SAVE dataset from 2003 on. Each year was imputed separately using a "Markov Chain Monte Carlo multiple imputation procedure" to fill the missing values with plausible substitutes. For a detailed description see Schunk (2008).

The first step of the complete imputation mechanism consists of a logical imputation. Logical imputation means that the true value of the missing value can be uniquely identified from within the dataset. The growing panel structure of the SAVE dataset offers new possibilities for logical imputation. This article documents the implementation of a logical imputation procedure for the SAVE data based on the waves from 2003 to 2008. The goal was to construct a transparent and traceable procedure, which allows the data user to evaluate the value added in the overall data accuracy. It should also demonstrate that data are not made-up. 
The outline of this article is as follows: Section 2 gives a brief overview of the German SAVE Survey and its panel dimension. Section 3 explains the procedure using different examples and presents the principles of logical imputation adopted. Section 4 summarizes the implemented methods and presents the results and the achievements in term of data accuracy. Section 5 concludes and gives a perspective for the further improvement of the imputation methods of the SAVE dataset.

\section{THE SAVE DATASET 2003-2008}

The SAVE survey started in 2001. The first year was used to build up the optimal survey design for the following years. Since 2005 the survey has been repeated on a yearly basis (figure 1). The complete sample is split into two parts: a Random Route sample, which is a multiple stratified multistage random sample, and an Access Panel, which is a quota sample. SAVE was especially designed to better understand the various aspects of the saving behavior of German households. For a detailed description of scientific background, design, and results the reader is referred to Schunk (2006) and Börsch-Supan et al. (2008).

Figure 1: Sample design of SAVE

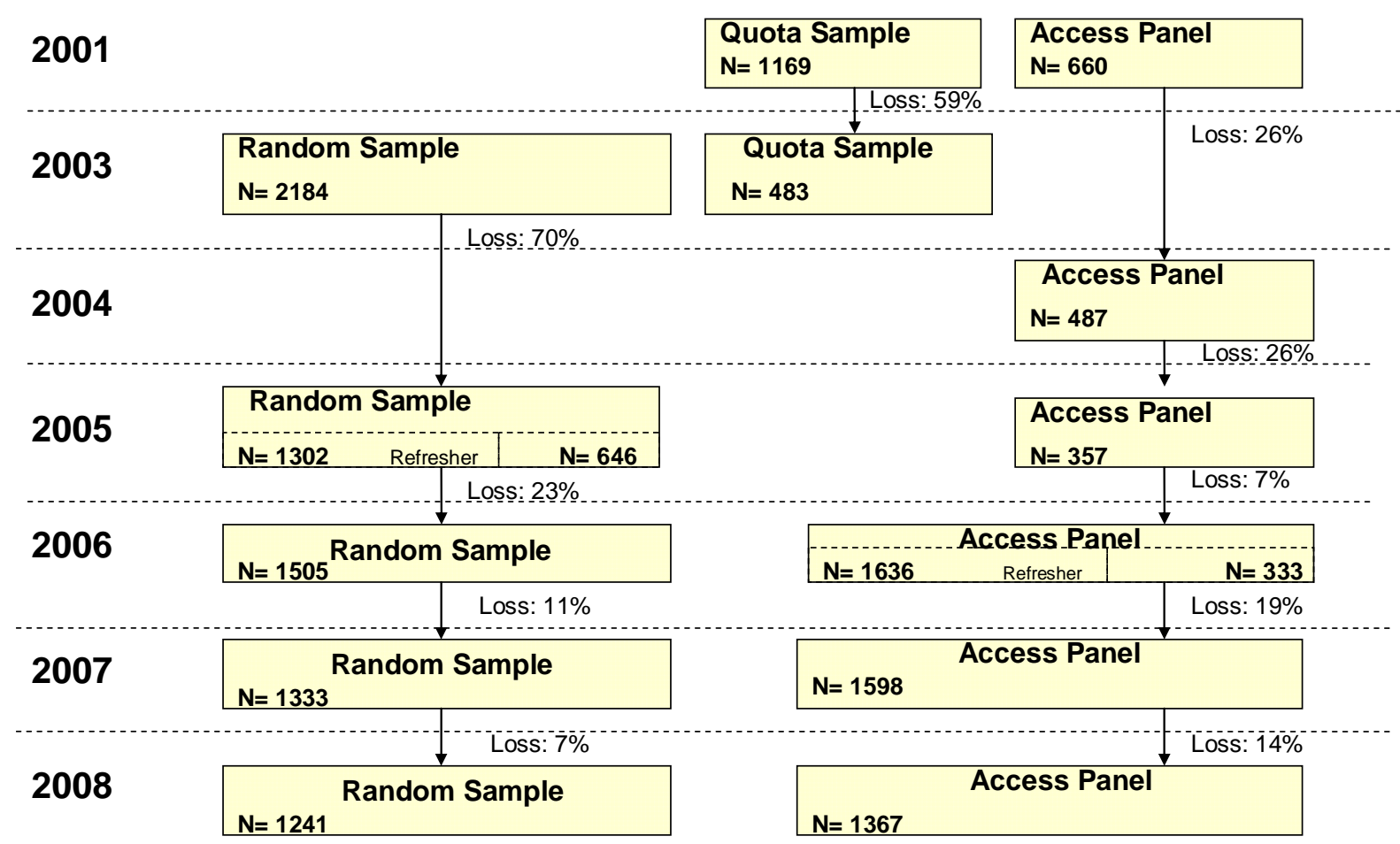


The key contributions of SAVE are the rich set of available control variables out of different areas like health, expectations, attitudes combined with detailed questioning about income, savings, debt and wealth. Moreover, SAVE is set up as a panel dataset and arrived at a fairly stable panel from 2006 on. Using a panel dataset, it is possible to distinguish between age and cohort effects, which is necessary for the empirical investigation of behavior over the lifecycle. The stable panel dimension allows for improving the data accuracy drastically. How this is done using the logical imputation is explained in the next section.

\section{Concept ANd Principles of the logical imputation}

Logical imputation as the first step of a cross-sectional imputation procedure is a frequently applied technique, e.g. in the German Socio-Economic Panel (Frick \& Grabka \& Marcus, 2007) and the SCF in the US (Kennickell, 1991). Only a few datasets use panel imputation methods, e.g. the British Household Panel Survey (Buck et al., 2006), the German SocioEconomic Panel (Frick \& Grabka, 2007) and the Household, Income and Labor Dynamics in Australia [Hilda] Survey (Starick, 2005): even these surveys, however, use panel estimation techniques only for specially chosen variables mainly out of the income section. In these cases, stochastic imputation procedures are generally applied. A logical longitudinal imputation was done in the case of the Canadian Survey of Labour and Income Dynamics (House, 2005). The questions about housing related content were imputed logically using the panel structure of the dataset if the postal code remained the same. In such cases it was assumed that the household did not move residence. The imputation method applied was a socalled "last value carried forward" method. For the SAVE dataset all sections were investigated for the application of a logical imputation using the panel structure, since the logical imputation allows replacing the missing values with a very high accuracy. 


\subsection{CONCEPT OF THE LOGICAL IMPUTATION}

To provide the reader with a better understanding what a logical imputation procedure does, three examples are discussed: one example for the cross-sectional context and two for the panel context.

In the 2008 questionnaire, question 6 can be translated as follows:

"Do you live with a partner on a permanent basis? Yes or no."

In the survey 2008, this question presented 21 missing values. Before running complicated imputation procedures, it is probably worth to check first if these respondents, who did not answer question 6 , reported somewhere else in the questionnaire useful information to fill in the missing value. Question 73, for example, provides, among others, the following response option: "Does not apply, do not have a partner." Choosing this option, the respondents implicitly report on their partner status, and the correct answer to question 6 can be reasonably derived from question 73. Indeed, using the information provided in this question, all the 21 missing values of question 6 can be filled up. In comparison with other imputation procedures, this way of proceeding has the advantage of relying only on the very mild assumption that the respondents consistently report the truth all over the questionnaire.

This way of filling up missing values in a cross-sectional context can be extended to a panel setting. In many cases, if the respondent provided the same answers in two years, but left a missing value in the year (or in the years) in between, it can be safely assumed that what he or she reported holds true also for the all years, so that the lacking data in one (or more) year(s) can be filled using the available answers. In some other questions, the structure of the possible answers allows to logically impute (at least part of) the missing values even when only a single observation is available. Two examples should help to clarify this concept.

As first example, a question out of the health section of the questionnaire is taken. All the respondents who report not to be currently smoking are asked the following question (number 30 of the 2008 questionnaire):

“Were you or your partner once a regular smoker? Yes or no.”

If identical answers in at least two points in time are available, and given that the respondent reported not to smoke also in the year(s) between the two observations, it is quite safe to impute the missing value(s) between the two observed values by simply carrying on the 
available answers. If in a certain year the respondent reported to have never regularly smoked in the past (so, if he or she answered "No" to the question), it is clear that this answer should be used to fill in the possible missings in the previous years (always conditioning on the current smoking behavior). Similarly, if in a certain year the respondent answered "Yes", the individual must be a regular smoker also in the future years (see table 1).

Table 1: Once a regular smoker - examples for logical imputation

\begin{tabular}{|c|c|c|c|c|c|}
\hline & $2003 / 04$ & 2005 & 2006 & 2007 & 2008 \\
\hline \multicolumn{6}{|c|}{ Possible structure of the answers before the logical imputation: } \\
\hline \multicolumn{6}{|l|}{ Are you currently smoking? } \\
\hline Individual 1, 2, 3 & No & No & No & No & No \\
\hline \multicolumn{6}{|l|}{ Were you once a regular smoker? } \\
\hline Individual 1 & Yes & Yes & - & - & Yes \\
\hline Individual 2 & - & - & - & No & - \\
\hline Individual 3 & - & - & Yes & - & - \\
\hline \multicolumn{6}{|c|}{ Structure of the answers after the logical imputation: } \\
\hline \multicolumn{6}{|c|}{ Are you currently smoking? } \\
\hline Individual 1, 2, 3 & No & No & No & No & No \\
\hline \multicolumn{6}{|l|}{ Were you once a regular smoker? } \\
\hline Individual 1 & Yes & Yes & YES & YES & Yes \\
\hline Individual 2 & NO & NO & NO & No & - \\
\hline Individual 3 & - & - & Yes & YES & YES \\
\hline
\end{tabular}

Note: Answers reported in capital, bold letters are meant to represent the logically imputed values. The dashes represent the missings.

The results for the household head and the corresponding partner are displayed in table 2. The overall missing rate can be reduced heavily. For the household head missing values can be reduced by around 45\% and for the partner by around 44\% over all years. In 2003 and 2004 there are no missing values available for the partner since this question was asked the first time in 2005.

Table 2: Once a regular smoker - result of logical imputation

numbers of missing values in each year

\begin{tabular}{|c|c|c|c|c|c|c|c|}
\hline household head & 2003 & 2004 & 2005 & 2006 & 2007 & 2008 & sum \\
\hline before log. imputation & 6 & 10 & 23 & 89 & 161 & 164 & 453 \\
\hline after log. imputation & 6 & 5 & 8 & 34 & 71 & 124 & 248 \\
\hline information gain & 0 & 5 & 15 & 55 & 90 & 40 & 205 \\
\hline \multicolumn{8}{|l|}{ partner } \\
\hline before log. imputation & - & - & 18 & 53 & 139 & 131 & 341 \\
\hline after log. imputation & - & - & 9 & 28 & 59 & 96 & 192 \\
\hline information gain & - & - & 9 & 25 & 80 & 35 & 149 \\
\hline
\end{tabular}


The second example uses a question about the individual's unemployment history. The following question was asked in all years of the SAVE survey, (number 21 in the 2008 questionnaire):

"Have you or your partner ever been registered as unemployed at the German State labor agency? If yes, what was the longest continuous period for which you were unemployed?

- Less than 1 month

- Between 1 and 6 months

- 6 to 12 months

- 1 to 2 years

- 2 years and more

- No, I have never registered as unemployed."

Again, the panel structure allows using the information given in one year to impute missing values in other years. If in a certain year, the respondent answered "No, I have never been registered as unemployed", it can be reasonably argued that the same respondent should never have been registered as unemployed also in the years before: as in the example above, the answer can therefore be taken to impute possible missings in previous years (and it goes without saying that the information cannot be used to impute possible missings in following years). Similarly, if in a certain year the respondent answered "2 years and more" of registered unemployment, the highest category should be carried on to future years (but of course not on previous years!). Again, in case the respondent provided the same answer, e.g. "6 to 12 months", in two years but left a missing value in the year (or years) in between, the lacking data can be filled with the available answer (see table 3).

Table 3: Registered unemployment - examples for logical imputation

\begin{tabular}{|c|c|c|c|c|c|}
\hline & 2003/04 & 2005 & 2006 & 2007 & 2008 \\
\hline \multicolumn{6}{|c|}{ Possible structure of the answers before the logical imputation: } \\
\hline Individual 1 & - & - & $\begin{array}{c}\text { Never } \\
\text { unemployed }\end{array}$ & 1 to 6 Months & 1 to 6 Months \\
\hline Individual 2 & $\begin{array}{l}6 \text { to } 12 \\
\text { Months }\end{array}$ & 1 to 2 Years & - & 1 to 2 Years & 1 to 2 Years \\
\hline Individual 3 & 1 to 2 Years & $\begin{array}{l}2 \text { or more } \\
\text { Years }\end{array}$ & $\begin{array}{l}2 \text { or more } \\
\text { Years }\end{array}$ & - & - \\
\hline
\end{tabular}




\begin{tabular}{|c|c|c|c|c|c|}
\hline \multicolumn{6}{|c|}{ Structure of the answers after the logical imputation: } \\
\hline Individual 1 & $\begin{array}{c}\text { Never } \\
\text { unemployed }\end{array}$ & $\begin{array}{c}\text { Never } \\
\text { unemployed }\end{array}$ & $\begin{array}{c}\text { Never } \\
\text { unemployed }\end{array}$ & 1 to 6 Months & 1 to 6 Months \\
\hline Individual 2 & $\begin{array}{l}6 \text { to } 12 \\
\text { Months }\end{array}$ & 1 to 2 Years & 1 to 2 Years & 1 to 2 Years & 1 to 2 Years \\
\hline Individual 3 & 1 to 2 Years & $\begin{array}{c}2 \text { or more } \\
\text { Years }\end{array}$ & $\begin{array}{l}2 \text { or more } \\
\text { Years }\end{array}$ & $\begin{array}{l}2 \text { or more } \\
\text { Years }\end{array}$ & $\begin{array}{l}2 \text { or more } \\
\text { Years }\end{array}$ \\
\hline
\end{tabular}

Note: Answers reported in capital, bold letters are meant to represent the logically imputed values. The dashes represent the missings.

Table 4: Registered unemployment - result of logical imputation

numbers of missing values in each year

\begin{tabular}{c|cccccccc}
\hline household head & $\mathbf{2 0 0 3}$ & $\mathbf{2 0 0 4}$ & $\mathbf{2 0 0 5}$ & $\mathbf{2 0 0 6}$ & $\mathbf{2 0 0 7}$ & $\mathbf{2 0 0 8}$ & sum \\
\hline \hline before log. imputation & 10 & 11 & 28 & 81 & 6 & 2 & 138 \\
& after log. imputation & 10 & 5 & 12 & 35 & 5 & 2 & 69 \\
$\quad$ information gain & 0 & 6 & 16 & 46 & 1 & 0 & $\mathbf{6 9}$ \\
\hline partner & & & & & & & \\
\hline \hline & before log. imputation & 46 & 9 & 44 & 71 & 12 & 10 & 192 \\
& after log. imputation & 43 & 5 & 20 & 33 & 11 & 10 & 122 \\
& information gain & 3 & 4 & 24 & 38 & 1 & 0 & $\mathbf{7 0}$
\end{tabular}

Table 4 displays the results of the logical imputation procedure outlined above. For the household head the overall number of missing values is halved. For the partner, the numbers of missing values are reduced by more than one third. Generally, the number of imputed missing values decreases with the years at the beginning (2003 and 2004) and the end (2008), and increases in the size of the panel component and the numbers of missings in each year.

The examples above illustrate the power of a proper logical imputation using the panel structure. The data quality can be improved drastically for some variables. Nevertheless, principles are needed to guide the implementation of the logical imputation to avoid the introduction of an excess of arbitrariness in the imputation procedure. These principles are discussed next.

\subsection{PRINCIPLES OF THE LOGICAL IMPUTATION}

Not all the questions in the survey are suitable for a logical imputation: questions about expectations, events during the last year, evaluation of current situations cannot be passively transferred across the years!

- The first step is therefore to identify the questions where a logical imputation using the panel structure can be implemented. For these questions, the logic of the 
imputation has to be singled out: can a certain answer be transferred to future as well as to past waves or can it be used only in one temporal direction? Is it possible to logically impute the answers when only a single observation in time is available, or can we impute only those missings between two observed values? However, there are same questions, for which one cannot be absolutely sure that the imposed logic is true for all respondents. There might be exceptions one cannot control for with other variables. In such cases the alternative would be to use a stochastic imputation procedure such as a hierarchical hot-deck method. However, this stochastic imputation procedure, which is only based on the information available in each cross-section so far, increases the variance between the years and can thus bias estimation results based on panel estimation techniques. Thus, there is a trade-off between imputing this question logically and reducing the variance over the years or using a stochastic imputation procedure and increasing the variances sometimes drastically over the years. This is a "question to question" and "cases to case" consideration and involves a careful examination of the underlying data.

- In a second step, this logic has to be proved. In other words, we have to check if, among those who answered the question in all the years, the logic that we assumed is indeed obeyed. Back to the first example: we hypothesize that individuals who once report to have been smokers in the past, should then consistently report the same also in the future. Looking at the data we then should ask: is that really the case? As a matter of questionnaires, you will always find inconsistent answers (i.e. individual who report to have been smokers in the past and that a year later report to have never smoked). However, this number has to be "reasonably" small.

- The third step involves the implementation of the logical imputation. In the best case, one can uniquely identify the missing value with the information offered by the other years. To reduce the degree of arbitrariness to a minimum, the missing value is not logically imputed, if the answers of a certain household are inconsistent over the years. The reason is that one cannot decide which of the answers is the "true" one. 


\section{OVERVIEW OVER IMPLEMENTATION AND RESULTS}

Since the logical imputation of each variable cannot be discussed in full length, table 5 summarizes the implementation in note form. The comments for each variable should give only a brief idea about the chosen procedure. The variable name corresponds to the variable name who is delivered with the datasets. Only the appendix “_imp” is missing since the variables refer to the still not imputed data. There are some exceptions mentioned in this table. These exceptions identify a possible violation of the assumed logic. Nevertheless, the logical imputation is done in these cases since the probability that these exception apply are found to be negligible small. ${ }^{2}$ Moreover, there are cases in which the logic would have allowed logically imputing more values. However, if there are too many cases in which the observed data are in contrast to the imposed logic, the variables, for which these inconsistencies are observed in a serious way, are not logically imputed. The comments of table 5 do not discuss explicitly these cases. Table 6 displays the results.

The five multiple imputed SAVE datasets are always delivered with an indicator datasets. Before the logical panel imputation was done, each variable in the indicator dataset flagged with " 1 ” implied a missing value and a variable flagged with " 0 ” an observed value. After the logical panel imputation was done, the flag-dataset was updated: "0" indicates an observed value, “1” implies a stochastically imputed missing value and "2" a logically imputed value using the panel structure. This procedure allows the researcher identifying the missing values and the imputation procedure used.

\footnotetext{
${ }^{2}$ For a deeper investigation the do-files will be provided on request.
} 
Table 5: Implementation

Var-Name Label

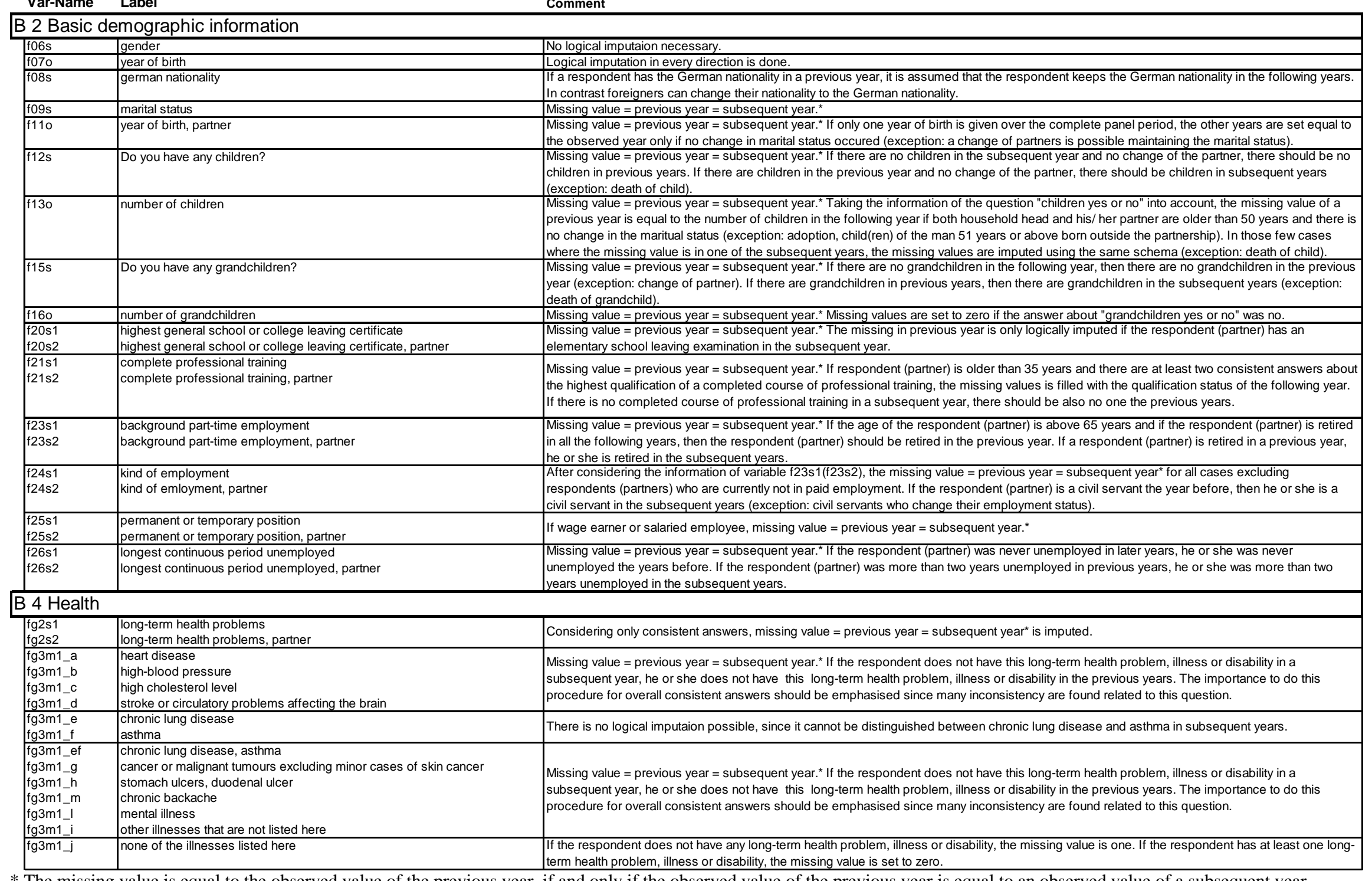

* The missing value is equal to the observed value of the previous year, if and only if the observed value of the previous year is equal to an observed value of a subsequent year. 


\begin{tabular}{|c|c|c|}
\hline $\begin{array}{l}\mathrm{fg} 3 \mathrm{~m} 2{ }_{-} \mathrm{a} \\
\cdots \\
\mathrm{fg} 3 \mathrm{~m} 2 \_\mathrm{j}\end{array}$ & $\begin{array}{l}\text { heart disease, partner } \\
\text { none of the illnesses listed here, partner }\end{array}$ & The same procedure as for the respondent is applied to the partner. \\
\hline †95s & regular smoker once? & $\begin{array}{l}\text { Missing value = previous year = subsequent year.* If the respondent was a regular smoker once in a previous year, he or she was a regular smoker } \\
\text { once in the subsequent years taking the actual smoking behavior into account. If the respondent was no regular smoker in a subsequent year, then } \\
\text { he or she was no regular smoker in the previous years. }\end{array}$ \\
\hline $\mathrm{f} 94 \mathrm{~s}$ & regular smoker? & Logical imputation uses only the information gained out of the question "once a regular smoker". \\
\hline $\begin{array}{ll}\text { f95s2 } \\
\mathrm{f94s2}\end{array}$ & $\begin{array}{l}\text { regular smoker once? - partner } \\
\text { regular smoker? - partner }\end{array}$ & The same procedure as for the respondent is applied to the partner. \\
\hline \multicolumn{3}{|c|}{ C 1 Savings } \\
\hline fes1s & refused credit or not granted credit & $\begin{array}{l}\text { Missing value = previous year = subsequent year (exception: five year horizon).* If the category "not applicable, Thave never asked for credit" is } \\
\text { chosen in a subsequent year, this status must also apply for the previous years. }\end{array}$ \\
\hline fes2s & not applied for credit because of believing that it would be refused & Missing value = previous year = subsequent year (exception: five year horizon).. \\
\hline $\mathrm{f48s}$ & record of household expenditure, parents & Missing value $=$ previous year $=$ subsequent year. ${ }^{\star}$ \\
\hline \multicolumn{3}{|c|}{ C 3 Income } \\
\hline $\begin{array}{l}f 53 m 1 \_k \\
f 53 m 1-n\end{array}$ & $\begin{array}{l}\text { pension from the public retirement insurance system } \\
\text { civil service pension }\end{array}$ & $\begin{array}{l}\text { Missing value = previous year = subsequent year. The respondent gets this pension in a previous year, he of she gets this pension also in the } \\
\text { subsequent years. If the respondent does not get this pension in a subsequent year, he or she does not get this pension in the previous years. This } \\
\text { logical imputation was only done for consistent answers over the years (exception: orphan's pension). }\end{array}$ \\
\hline 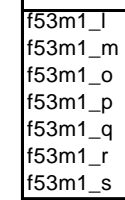 & $\begin{array}{l}\text { additional provision from civil service scheme } \\
\text { company pension } \\
\text { agricultural pension scheme } \\
\text { occupational pension schemes } \\
\text { pension deriving from a life insurance policy } \\
\text { pension from private pension policies } \\
\text { other pensions }\end{array}$ & $\begin{array}{l}\text { Missing value = previous year }=\text { subsequent year. }{ }^{*} \text { If the respondent does not get this pension in a subsequent year, he or she does not get this } \\
\text { pension in the previous years. This is only done for overall consistent answers. }\end{array}$ \\
\hline $753 \mathrm{~m} 1{ }_{-} \mathrm{t}$ & no, none of these - no independent income & $\begin{array}{l}\text { If all types of current income sources are not paid, the missing value is one. If at least one type of retirement income is paid, the missing value is set } \\
\text { to zero. }\end{array}$ \\
\hline \begin{tabular}{l}
$F 53 m 2 \_k$ \\
$\cdots$ \\
\hdashline $53 m 2 \_t$
\end{tabular} & $\begin{array}{l}\text { pension from the public retirement insurance system, partner } \\
\text { no, none of these - no independent income, partner }\end{array}$ & The same procedure as for the respondent is applied to the partner. \\
\hline \multicolumn{3}{|c|}{ D 2 Old-age provision } \\
\hline$\frac{f 60 \mathrm{~s}}{\mathrm{f} 60 \mathrm{o}}$ & $\begin{array}{l}\text { single retired? } \\
\text { single retired since? }\end{array}$ & If the respondent is not retired in a subsequent year, then the respondent is not retired in the previous years. \\
\hline$\frac{f 600}{f 61 s}$ & $\begin{array}{l}\text { single retired, since? } \\
\text { couple retired? }\end{array}$ & $\begin{array}{l}\text { Logical imputation in every direction possible considering consistent answer in all years the respondent answered this question. } \\
\text { If a couple is not retired in a subsequent year, then the couple is not retired in the previous years. }\end{array}$ \\
\hline $\begin{array}{l}f 6101 \\
f 6102 \\
f 6103 \\
f 6104\end{array}$ & $\begin{array}{l}\text { couple, both retired: since? - interviewed person } \\
\text { couple, both retied since? - partner } \\
\text { couple, only interviewed person retired: since? } \\
\text { couple, only partner retired: since? }\end{array}$ & Logical imputation in every direction possible considering consistent answer in all years the respondent answered this question. \\
\hline 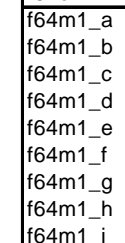 & $\begin{array}{l}\text { pension from the state pension insurance scheme } \\
\text { additional provision from civil service scheme } \\
\text { company pension } \\
\text { civil service pension } \\
\text { agricultural pension scheme } \\
\text { occupational pension schemes for self-employed people } \\
\text { pension deriving from a life insurance policy } \\
\text { pension from private pension policies } \\
\text { other pensions }\end{array}$ & Missing value $=$ previous year $=$ subsequent year. ${ }^{*}$ \\
\hline f64m1_j & none of these - no independent income & $\begin{array}{l}\text { If all types of retirement income are not paid, the missing value is one. If at least one type of retirement income is paid, the missing value is set to } \\
\text { zero. }\end{array}$ \\
\hline $\begin{array}{l}64 \mathrm{~m} 2 \_a \\
\cdots \\
664 \mathrm{~m} 2 \mathrm{j}\end{array}$ & $\begin{array}{l}\text { pension from the state pension insurance scheme - partner } \\
\text { none of these - no independent income - partner }\end{array}$ & The same procedure as for the respondent is applied to the partner. \\
\hline $772 s \_10$ & owner Rister- or Rürup-Pension & $\begin{array}{l}\text { Variable frr1s (question } 100 \text { in the } 2008 \text { questionnaire) is used to logically impute this question. However, guestion } 100 \text { refers only to the Riester- } \\
\text { Pension. Therefore, the imputation is additional conditioned on current profession. The logical imputation does not take place for self-employed or } \\
\text { freelancer (exception: not only self-employed or freelancers could posses a Rürup-Pension). }\end{array}$ \\
\hline
\end{tabular}




\section{Table 6: Results}

\begin{tabular}{|c|c|c|c|c|c|c|c|c|c|c|c|c|c|c|c|}
\hline \multirow[b]{2}{*}{ Var-Name } & \multirow[b]{2}{*}{ Label } & \multirow[b]{2}{*}{03} & \multirow[b]{2}{*}{04} & \multicolumn{4}{|c|}{$\begin{array}{l}\text { missing values } \\
\text { before log. Imputation }\end{array}$} & \multicolumn{2}{|c|}{$\begin{array}{l}\text { information } \\
\text { gain }\end{array}$} & \multicolumn{4}{|c|}{$\begin{array}{l}\text { missing values } \\
\text { after log. Imputation }\end{array}$} & \multirow[b]{2}{*}{07} & \multirow[b]{2}{*}{08} \\
\hline & & & & 05 & 06 & 07 & 08 & abs & in $\%$ & 03 & 04 & 05 & 06 & & \\
\hline \multicolumn{16}{|c|}{ B 2 Basic demographic information } \\
\hline fo6s & gender & 0 & 0 & 0 & 0 & 0 & 0 & 0 & $0 \%$ & 0 & 0 & 0 & 0 & 0 & 0 \\
\hline$f 070$ & year of birth & 0 & 0 & 16 & 1 & 0 & 0 & 11 & $65 \%$ & 0 & 0 & 6 & 0 & 0 & 0 \\
\hline f08s & german nationality & 1 & 0 & 9 & 3 & 1 & 0 & 10 & $71 \%$ & 1 & 0 & 0 & 2 & 1 & 0 \\
\hline f09s & marital status & 3 & 0 & 2 & 11 & 23 & 21 & 23 & $38 \%$ & 3 & 0 & 2 & 6 & 5 & 21 \\
\hline f110 & year of birth, partner & 8 & 0 & 8 & 6 & 13 & 6 & 14 & $34 \%$ & 7 & 0 & 6 & 3 & 5 & 6 \\
\hline f12s & Do you have any children? & 4 & 1 & 9 & 58 & 62 & 22 & 107 & $69 \%$ & 4 & 0 & 3 & 13 & 8 & 21 \\
\hline $\mathrm{f130}$ & number of children & 8 & 5 & 12 & 99 & 129 & 62 & 178 & $57 \%$ & 8 & 0 & 3 & 30 & 42 & 54 \\
\hline f15s & Do you have any grandchildren? & 4 & 1 & 13 & 94 & 125 & 68 & 206 & $68 \%$ & 4 & 0 & 3 & 20 & 30 & 42 \\
\hline f16o & number of grandchildren & 6 & 1 & 18 & 101 & 137 & 75 & 155 & $46 \%$ & 6 & 0 & 7 & 35 & 60 & 75 \\
\hline $120 \mathrm{~s} 1$ & highest general school or college leaving certificate & 11 & 0 & 16 & 8 & 3 & 3 & $\frac{60}{6}$ & $15 \%$ & 9 & 0 & 13 & 7 & 3 & 3 \\
\hline $\mathrm{f} 20 \mathrm{~s} 2$ & highest general school or college leaving certificate, partner & 42 & 1 & 14 & 15 & 7 & 7 & 4 & $5 \%$ & 41 & 1 & 14 & 13 & 6 & 7 \\
\hline f21s1 & complete professional training & 3 & 3 & 153 & 9 & 1 & 0 & 91 & $54 \%$ & 3 & 2 & 72 & 1 & 0 & 0 \\
\hline f21s2 & complete professional training, partner & 34 & 1 & 94 & 16 & 5 & 6 & 45 & $29 \%$ & 34 & 1 & 52 & 13 & 5 & 6 \\
\hline f23s1 & background part-time employment & 41 & 15 & 68 & 143 & 84 & 59 & 82 & $20 \%$ & 41 & 11 & 58 & 121 & 51 & 46 \\
\hline f23s2 & background part-time employment, partner & 31 & 29 & 64 & 198 & 92 & 66 & 109 & $23 \%$ & 31 & 28 & 49 & 149 & 62 & 52 \\
\hline f24s1 & kind of employment & 5 & 7 & 65 & 146 & 68 & 69 & 36 & $10 \%$ & 5 & 7 & 62 & 123 & 61 & 66 \\
\hline $\mathrm{f24 \textrm {s } 2}$ & kind of emloyment, partner & 9 & 5 & 31 & 122 & 52 & 52 & 28 & $10 \%$ & 9 & 5 & 28 & 106 & 43 & 52 \\
\hline $\mathrm{f25s1}$ & permanent or temporary position & 7 & 8 & 80 & 199 & 88 & 88 & 45 & $10 \%$ & 7 & 8 & 75 & 174 & 76 & 85 \\
\hline $\mathrm{f25s2}$ & permanent or temporary position, partner & 11 & 6 & 37 & 138 & 67 & 67 & 37 & $11 \%$ & 11 & 6 & 33 & 120 & 52 & 67 \\
\hline f26s1 & longest continuous period unemployed & 10 & 11 & 28 & 81 & 6 & 2 & 69 & $50 \%$ & 10 & 5 & 12 & 35 & 5 & 2 \\
\hline $\mathrm{f} 26 \mathrm{~s} 2$ & longest continuous period unemployed, partner & 46 & 9 & 44 & 71 & 12 & 10 & 70 & $36 \%$ & 43 & 5 & 20 & 33 & 11 & 10 \\
\hline \multicolumn{16}{|l|}{ B 4 Health } \\
\hline $\lg 2 \mathrm{~s} 1$ & long-term health problems & - & - & 19 & 65 & 61 & 72 & 45 & $21 \%$ & - & $=$ & 19 & 53 & 28 & 72 \\
\hline fg2s2 & Iong-term health problems, partner & - & - & 21 & 53 & 47 & 56 & 26 & $15 \%$ & - & - & 21 & 42 & 32 & 56 \\
\hline $\operatorname{fg} 3 \mathrm{~m} 1 \_\mathrm{a}$ & heart disease & - & - & 53 & 374 & 197 & 256 & 442 & $50 \%$ & - & - & 15 & 94 & 73 & 256 \\
\hline fg3m1_b & high-blood pressure & - & - & 53 & 374 & 197 & 256 & 422 & $48 \%$ & - & - & 19 & 102 & 81 & 256 \\
\hline fg3m1_c & high cholesterol level & - & - & 53 & 374 & 197 & 256 & 435 & $49 \%$ & - & . & 15 & 97 & 77 & 256 \\
\hline $\operatorname{fg} 3 m 1-d$ & stroke or circulatory problems affecting the brain & & - & 53 & 374 & 197 & 256 & 454 & $52 \%$ & . & . & 14 & 86 & 70 & 256 \\
\hline fg3m1 e & chronic lung disease & . & . & 53 & - & - & - & 0 & $0 \%$ & . & . & 53 & - & - & - \\
\hline $\operatorname{fg} 3 \mathrm{~m} 1 \mathrm{f}$ & asthma & - & - & 53 & . & - & . & 0 & $0 \%$ & - & . & 53 & . & & - \\
\hline fg3m1_ef & chronic lung disease, asthma & ( & & & 374 & 197 & 256 & 387 & $47 \%$ & & & & 103 & 81 & 256 \\
\hline fg3m1_g & cancer or malignant tumours excluding minor cases of skin cancer & . & . & 53 & 374 & 197 & 256 & 454 & $52 \%$ & . & - & 14 & 86 & 70 & 256 \\
\hline 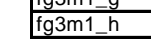 & \begin{tabular}{|l} 
stomach ulcers, duodenal ulcer \\
\end{tabular} & - & . & 53 & 374 & 197 & 256 & 454 & $52 \%$ & - & : & 14 & 85 & 71 & 256 \\
\hline fg3m1_m & chronic backache & - & & & 374 & 197 & 256 & 387 & $47 \%$ & - & & & 103 & 81 & 256 \\
\hline fg3m1_I & mental illness & - & - & - & 374 & 197 & 256 & 407 & $49 \%$ & - & - & - & 93 & 71 & 256 \\
\hline fg3m1 i & other illnesses that are not listed here & - & - & 53 & 374 & 197 & 256 & 380 & $43 \%$ & - & - & 25 & 129 & 90 & 256 \\
\hline $\mathrm{fg} 3 \mathrm{~m} 1 \mathrm{j}$ & none of the illnesses listed here & - & - & 53 & 374 & 197 & 256 & 347 & $39 \%$ & - & - & 38 & 138 & 101 & 256 \\
\hline$\frac{y}{\mathrm{fg} 3 \mathrm{~m} 2 \mathrm{a}}$ & heart disease, partner & - & - & 919 & 290 & 184 & 206 & 907 & $57 \%$ & - & - & 310 & 93 & 83 & 206 \\
\hline $\mathrm{fg} 3 \mathrm{~m} 2 \mathrm{~b}$ & high-blood pressure, partner & 然 & 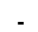 & 919 & 290 & 184 & 206 & 755 & $47 \%$ & 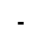 & . & 440 & 110 & 88 & 206 \\
\hline fg3m2 c & high cholesterol level, partner & - & . & 919 & 290 & 184 & 206 & 823 & $51 \%$ & - & . & 376 & 106 & 88 & 206 \\
\hline $\mathrm{fg} 3 \mathrm{~m} 2 \mathrm{~d}$ & stroke or circulatory problems affecting the brain, partner & . & . & 919 & 290 & 184 & 206 & 931 & $58 \%$ & - & . & 288 & 91 & 83 & 206 \\
\hline fg3m2 e & chronic lung disease, partner & 列 & & 919 & & & & 0 & $0 \%$ & & & 919 & & & \\
\hline 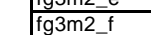 & asthma, partner & . & . & 919 & . & . & . & 0 & $0 \%$ & - & . & 919 & . & . & :- \\
\hline fg3m2 ef & chronic lung disease, asthma, partner & . & . & & 290 & 184 & 206 & 298 & $44 \%$ & - & . & & 93 & 83 & 206 \\
\hline fg3m2_g & cancer or malignant tumours excluding minor cases of skin cancer, partner & - & - & 919 & 290 & 184 & 206 & 910 & $57 \%$ & - & - & 308 & 92 & 83 & 206 \\
\hline fg $3 m 2 h$ & stomach ulcers, duodenal ulcer, partner & - & - & 919 & 290 & 184 & 206 & 922 & $58 \%$ & - & - & 295 & 93 & 83 & 206 \\
\hline fg $3 m 2$ & chronic backache, partner & ( & 烈 & & 290 & 184 & 206 & 271 & $40 \%$ & - & - & & 105 & 98 & 206 \\
\hline fg $3 \mathrm{~m} 21$ & mental illness, partner & - & - & - & 290 & 184 & 206 & 294 & $43 \%$ & - & - & - & 92 & 88 & 206 \\
\hline $\mathrm{fg} 3 \mathrm{~m} 2 \mathrm{i}$ & other illnesses that are not listed here, partner & - & - & 919 & 290 & 184 & 206 & 706 & $44 \%$ & - & - & 465 & 117 & 105 & 206 \\
\hline famm2 & none of the illnesses listed here, partner & - &. & 919 & 290 & 184 & 206 & 673 & $42 \%$ & - & ( & 511 & 106 & 103 & 206 \\
\hline
\end{tabular}




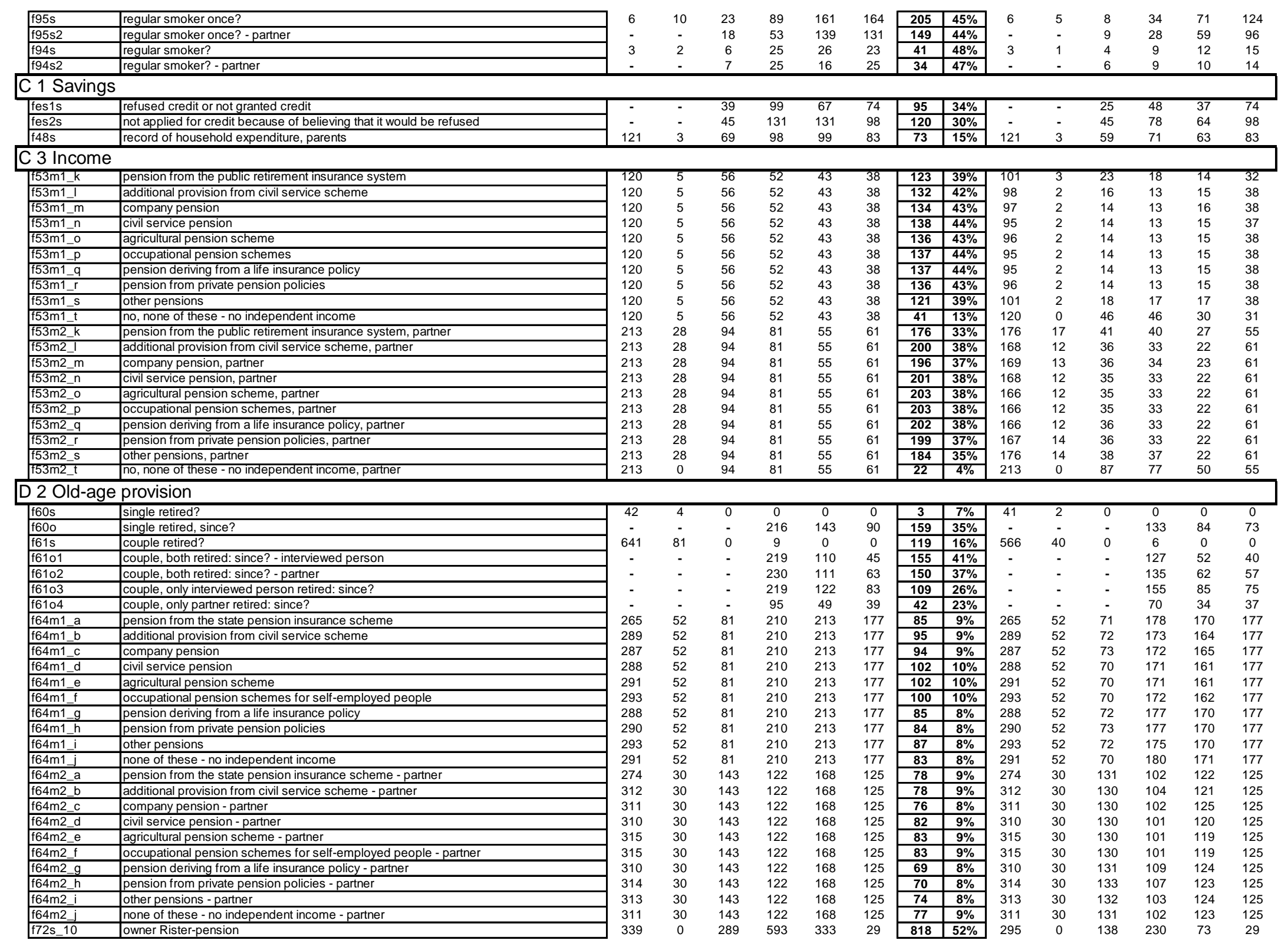




\section{CONCLUSION}

This paper documented the implementation of a logical panel imputation of the 2003 to 2008 waves of the German SAVE study. After briefly introducing the SAVE dataset, the concept of logical imputation was clarified using different examples. The principles of the underlying logical panel imputation were discussed. Compared to stochastic imputation procedures, a great advantage of the logical panel imputation is the mild assumption that the respondent consistently reports the truth over all the years. After giving a short overview of all the variables logically imputed using the panel structure and a comment about the chosen method, table 6 showed how many missing values could be filled. For remarkably many variables the number of missing values could be reduced by more than 50\%. Thus, the applied logical panel imputation improved the quality of the SAVE data notably.

Using the panel dimension of the SAVE dataset can be seen as a first step towards a complete multiple panel imputation procedure. So far the logical imputation in each cross-section and the subsequently logical imputation over the waves 2003-2008 was the starting position for the "Markov Chain Monte Carlo multiple imputation procedure" in each cross-section. This procedure has been improved over the years and was recently standardized. Now, all the datasets from 2003 to 2008 are based on the same imputation procedure, which allows a consistent treatment of all waves using panel estimation techniques. ${ }^{3}$ A challenging and work intensive improvement would be a multiple panel imputation. This would not only allow increasing the accuracy of the estimations but also preserving the correlation structure over the years.

\footnotetext{
${ }^{3}$ The consistently imputed datasets will be available around July 2009. For more information please have a look at the MEA homepage: http://www.mea.uni-mannheim.de/
} 


\section{LITERATURE}

Börsch-Supan, A., M. Coppola, L. Essig, A. Eymann, and D. Schunk (2008): "The German SAVE study. Design and Results." Mea Studies 06, MEA-Mannheim Research Institute for the Economics of Aging, University of Mannheim.

Buck, N. et al. (2006): "Quality Profile: British Household Panel Survey. Version 2.0: Waves 1 to 13: 1991-2003." Institute for Social and Economic Research, University of Essex.

Frick, J. R. and Grabka, M. M. (2007): "Item non-response and Imputation of Annual Labor Income in Panel Surveys from a Cross-National Perspective." DIW Discussion Paper 736.

Frick, J. R., M. M. Grabka, and J. Marcus (2007): "Editing and Multiple Imputation of ItemNon-Response in the 2002 Wealth Module of the German SOEP." Data Documentation 18, Berlin: German Institute for Economic Research (DIW).

House, G. (2005): "General Housing Imputation (excluding utilities) in the Survey of Labour and Income Dynamics (SLID)." Income Research Paper Series, Statistics Canada, Catalogue no. 75F0002MIE — No. 010.

Kennickell, A. B. (1991): "Imputation of the 1989 Survey of Consumer Finances: Stochastic Relaxation and Multiple Imputation." Proceedings of the Section on Survey Research Methods, American Statistical Association. Atlanta, Georgia.

Rässler, S. and R. Riphahn (2006): "Survey item nonresponse and its treatment." Allgemeines Statistisches Archiv, 90, 217 - 232.

Schunk, D. (2006): "The German SAVE Survey 2001 - 2006. Documentation and Methodology. " Mea-Discussion-Paper 109-2006, MEA-Mannheim Research Institute for the Economics of Aging, University of Mannheim.

Schunk, D. (2008): "A Markov chain Monte Carlo algorithm for multiple imputation in large surveys." Advances in Statistical Analysis, 92(1), 101 - 114.

Starick, R. (2005): "Imputation in Longitudinal Surveys: The Case of HILDA." Research Paper of the Australian Bureau of Statistics. ABS Catalogue no. 1352.0.55.075. 


\section{Discussion Paper Series}

Mannheim Research Institute for the Economics of Aging Universität Mannheim

To order copies, please direct your request to the author of the title in question.

\begin{tabular}{|c|c|c|c|}
\hline Nr. & Autoren & Titel & Jahr \\
\hline $161-08$ & Karsten Hank & Generationenbeziehungen im alternden Europa & 08 \\
\hline $162-08$ & $\begin{array}{l}\text { Axel Börsch-Supan, } \\
\text { Karsten Hank, } \\
\text { Hendrik Jürges, } \\
\text { Mathis Schröder }\end{array}$ & $\begin{array}{l}\text { Longitudinal Data Collection in Continental } \\
\text { Europe: Experiences from the Survey of Health, } \\
\text { Ageing and Retirement in (SHARE) }\end{array}$ & 08 \\
\hline $163-08$ & Martin Salm & Job loss does not cause ill health & 08 \\
\hline $164-08$ & $\begin{array}{l}\text { Martin Salm, Daniel } \\
\text { Schunk }\end{array}$ & $\begin{array}{l}\text { The role of childhood health for the inter- } \\
\text { generational transmission of human capital: } \\
\text { Evidence from administrative data }\end{array}$ & 08 \\
\hline $165-08$ & Christina Benita Wilke & $\begin{array}{l}\text { On the feasibility of notional defined contribution } \\
\text { systems: The German case }\end{array}$ & 08 \\
\hline $166-08$ & $\begin{array}{l}\text { Alexander Ludwig } \\
\text { Michael Reiter }\end{array}$ & $\begin{array}{l}\text { Sharing Demographic Risk - Who is Afraid of } \\
\text { the Baby Bust? }\end{array}$ & 08 \\
\hline $167-08$ & $\begin{array}{l}\text { Jürgen Maurer } \\
\text { André Meier }\end{array}$ & $\begin{array}{l}\text { Smooth it Like the "Joneses?" Estimating Peer- } \\
\text { Group Effects in Intertemporal Consumption } \\
\text { Choice }\end{array}$ & 08 \\
\hline $168-08$ & $\begin{array}{l}\text { Melanie Lührmann } \\
\text { Jürgen Masurer }\end{array}$ & $\begin{array}{l}\text { Who wears the trousers? A semiparametric } \\
\text { analysis of decision power in couples }\end{array}$ & 08 \\
\hline $170-08$ & Jürgen Maurer & $\begin{array}{l}\text { Who has a clue to preventing the flu? } \\
\text { Unravelling supply and demand effects on the } \\
\text { take-up of influenza vaccinations }\end{array}$ & 08 \\
\hline $171-08$ & $\begin{array}{l}\text { Johannes Binswanger } \\
\text { Daniel Schunk }\end{array}$ & $\begin{array}{l}\text { What Is an Adequate Standard of Living } \\
\text { during Retirement? }\end{array}$ & 08 \\
\hline $172-08$ & $\begin{array}{l}\text { Mathis Schröder } \\
\text { Axel Börsch-Supan }\end{array}$ & Retrospective Data Collection in Europe & 08 \\
\hline $173-09$ & Michael Ziegelmeyer & $\begin{array}{l}\text { Documentation of the logical imputation using } \\
\text { the panel structure of the } 2003-2008 \text { German } \\
\text { SAVE Survey }\end{array}$ & 09 \\
\hline
\end{tabular}

